\title{
Steel mould surface improvement by robot fluid jet polishing and robot pad polishing for polymer optic production
}

\author{
Rui Almeida ${ }^{1, *}$, Timon Ebert $^{1}$, Rainer Börret $^{1}$ and Mario Pohl $^{1}$ \\ ${ }^{1}$ Aalen University of Applied Sciences, Centre for Optical Technologies, 73430 Aalen, Germany
}

\begin{abstract}
In order to improve the quality of injection-moulded polymer optic parts, it is necessary to improve the quality of the respective steel moulds. For this reason, it is not only necessary to improve the surface roughness of the mould, but also its geometrical shape. The material removal obtained from robot pad polishing is too low. This makes a shape correction after the milling step a very prolonged process. The aim of this work is to use a polishing chain to improve the surface quality of steel samples in terms of shape deviation and surface roughness. This correction polishing chain uses the robot fluid jet polishing for the geometrical shape correction and afterwards the robot pad polishing for the improvement of the surface roughness. Due to the high material removal rates of the fluid jet polishing, it is possible to correct the geometrical shape of steel moulds very fast up to a certain deviation. The pad polishing process improves the surface roughness of the steel samples. A correction of the shape deviation of more than $80 \%$ with a RMS of approximately $8 \mathrm{~nm}$ was obtained.
\end{abstract}

\section{Introduction}

The quality of plastic parts, produced with the plastic injection moulding process, depends on the shape deviation and the surface roughness of the respective mould [1]. This is due to the fact that the produced parts acquire the geometry of the respective mould. Most plastic injection moulding parts use a steel mould tool, which is usually still polished by hand [2]. For this reason the polishing process step accounts for up to $30 \%$ of the total costs in the mould manufacturing process. This makes the polishing a very time consuming and expensive process step [3]. The reproducibility of good manual polishing results depends on the workers skill, his form on the day, patience, experience and concentration as mentioned by Klocke [4]. Automatic robotic polishing processes were increasing over the years, replacing manual operations to automated processes as stated by Segreto [5]. Therefore, industry is giving more importance to finishing processes on curved surfaces concerning good surface quality, efficiency and low cost as described by Tian [6]. The surface roughness of steel moulds has already been improved up to $3 \mathrm{~nm}$ using the robot as an automatized polishing process [7]. In order to decrease the production time of the final part in the plastic injection moulding process, the steel moulds geometrical shape also needs to be optimized. In previous works [8], it was possible to correct the geometrical shape of flat hardened steel samples from $668.8 \mathrm{~nm}$ to $214.2 \mathrm{~nm}$ by using the robot pad polishing process. This represents an improvement of $68 \%$. Despite the successful correction and its prediction, this process is very time consuming. The material removal rate per time is very low during the robot pad polishing process. The already known robot fluid jet polishing process is used to reduce the correction time of steel moulds during the polishing phase. The fluid jet polishing process uses water mixed with abrasive grains, which is pumped in a closed circuit, and is jetted with a certain pressure on the surface. Figure 1 shows the fluid jet polishing principle.

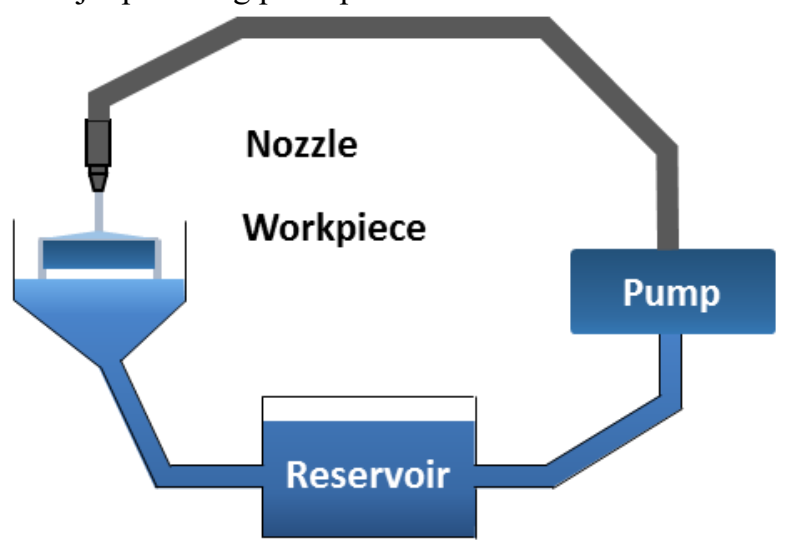

Fig. 1. Principle of the fluid jet polishing process

The material removal on the surface is generated by shear forces that occur upon impact. This polishing process has the advantage of using a very small tool function compared to the robot pad polishing process. Besides that, there is also no wear on the tool compared to the robot pad polishing process. The fluid jet polishing process is used to correct the geometrical shape and the pad polishing process is used to improve the surface roughness of the steel samples, in order to produce a surface with a good quality in terms of shape and roughness.

*Corresponding author: rui.almeida@hs-aalen.de 


\section{Aims of this research}

The objective of this investigation is to use the knowledge obtained from previous works and improve the surface quality of steel samples, in terms of shape and roughness. The polishing correction technique is applied using the fluid jet polishing process to improve the shape deviation. In this technique, the movement of the robot is manipulated using a feed rate profile. This feed rate profile takes into account the actual shape, the desired shape, the polishing tool function and the desired moving method. The principle of this technique is that on hikes of the surface the movement speed of the robot is decreased in order to create a higher material removal, while on wells the movement speed is increased to create less material removal.

To improve the surface roughness of the steel samples the robot pad polishing process is used. With the current fluid jet polishing process it is only possible to achieve a surface roughness between 200 and $400 \mathrm{~nm}$ on a milled surface, for this reason the pad polishing process is used to improve the surface roughness below $10 \mathrm{~nm}$. In order to obtain precise measurements, a Fizeau Interferometer was chosen as optical measuring technique. In order to optically measure a surface a glossy surface is needed. For this reason, the samples were lapped to approximately $10 \mathrm{~nm}$ RMS and measured afterwards, afterwards they were fluid jetted and afterwards pad polished. The following figure 2 shows the surface roughness after the fluid jet polishing(A) and after the pad polishing(B). The surface roughness after the fuid jet polishing was between 70 and $100 \mathrm{~nm}$, and after the pad polishing the surface roughness was below $10 \mathrm{~nm}$.

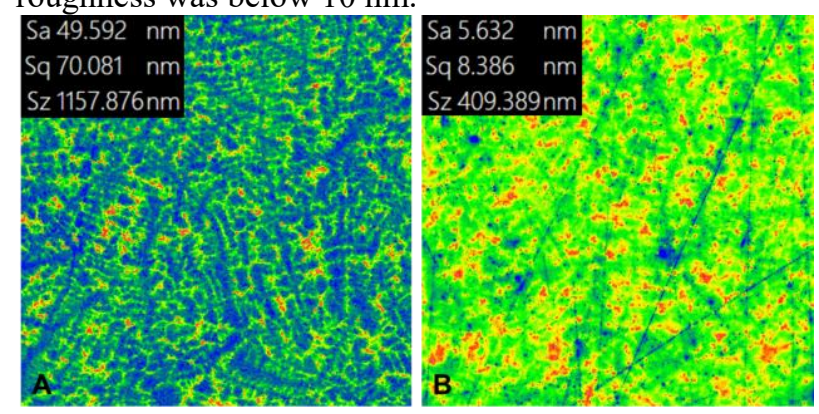

Fig. 2. Surface roughness after fluid jet polishing(A) and after pad polishing(B)

Figure 2 shows the results obtained during the application of the polishing correction technique. The shape deviation before the polishing process was around 963,7 nm and afterwards, the surface was improved up to $115,7 \mathrm{~nm}$.

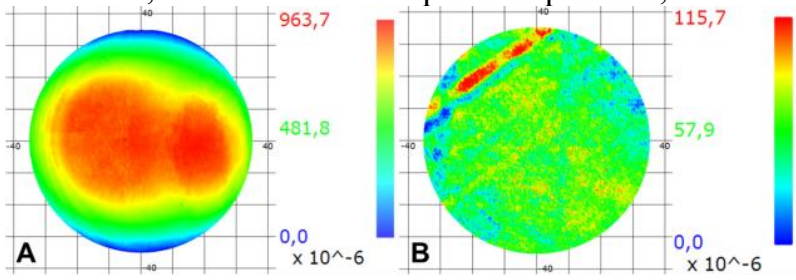

Fig. 3. Shape error before the polishing correction(A) and after polishing correction(B)

\section{Conclusions}

It was possible to improve the surface quality of steel samples in terms of surface roughness and shape deviation. It was possible to reduce the working/polishing time compared to previous works[8]. Considering the shape deviation, the error of the sample was $963,7 \mathrm{~nm}$ in the beginning. After the polishing correction technique it was improved up to $115,7 \mathrm{~nm}$, which is an improvement of more than $85 \%$. This improvement shows the correction capabilities of the fluid jet polishing process as it is possible to create constant and reproducible material removals with a high removal rate per time. Comparing the robot pad polishing process with the robot fluid jet polishing process, there is a material removal factor of 25 . This means that the fluid jet polishing is able to produce 25 more material removal in the same amount of time compared to the pad polishing process.

Considering the surface roughness, after the fluid jet polishing the roughness of the sample was between $70 \mathrm{~nm}$ up to $100 \mathrm{~nm}$ RMS. With the pad polishing process it was possible to improve it up to $5 \mathrm{~nm}$ RMS. It was concluded that it is possible to combine the fluid jet polishing process with the pad polishing process for the production of steel moulds. The fluid jet polishing is well suited to improve the shape deviation and the pad polishing to improve the surface roughness. In the end, the steel sample's surface had a RMS of $5 \mathrm{~nm}$ and $100 \mathrm{~nm}$ shape deviation.

\section{References}

1. M. Speich, R. Boerret, Mould fabrication for polymer optics (Journal of the European Optical Society: Rapid Publications, 6, 2011)

2. R. Boerret, J. Klingenmaier, U. Berger, A. Frick, Minimized process chain for polymer optics (Proceedings of SPIE, San Diego, California, United States, 2008)

3. A. Uddeholm, Uddeholm Tool Steel for Moulds, (2016)

4. F. Klocke, O. Dambon, B. Behrens, Analysis of defect mechanisms in polishing of tool steels (Production Engineering Research and Development, 2011)

5. T. Segreto, S. Karam, R. Teti, J. Ramsing, Feature Extraction and Pattern Recognition in Acoustic Emission Monitoring of Robot Assisted Polishing, Procedia CIRP, 2015)

6. F. Tian, C. LV, Z. Li, G. Liu, Modeling and control of robotic automatic polishing for curved surfaces (CIRP Journal of Manufacturing Science and Technology, 2016)

7. R. Boerret, J. Raab, M. Speich, Mold production for polymer optics (Proceedings SPIE, 2014)

8. R. Almeida, R. Boerret, M. Pohl, D. K. Harrison, A. K. M. DeSilva, Geometrical shape improvement of steel moulds by robot polishing process for polymer optic replication (Production \& Manufacturing Research, 2018) 